\title{
Temporal Trends in Vaping Use: \\ Demographic Diversity and Healthcare Utilization Outcomes
}

Trevor Nguyen, BS; ${ }^{\mathrm{a}}$ Teodora Nikova, BS; ${ }^{\mathrm{b}}$ Eric Luong, MPH; ${ }^{\mathrm{a}}$ Patrick Bottling, MS; ${ }^{\mathrm{a}}$

Mir Henglin, BA; ${ }^{a}$ Elizabeth H. Kim, BA; ${ }^{a}$ Florian Rader, MD, MSc; ${ }^{a}$ Itai Danovitch, MD, MBA; Aaron Weinberg, MD, MPhil; Susan Cheng, MD, MMSc, MPH; Joseph Ebinger, MD, MS ${ }^{\text {a }}$

From the: a Smidt Heart Institute, Cedars-Sinai Medical Center, Los Angeles, CA; ${ }^{b}$ Northeast Ohio Medical University, School of Medicine, Rootstown, Ohio; 'Department of Psychiatry and Behavior Neurosciences, Cedars-Sinai Medical Center, Los Angeles, CA; and, ${ }^{d}$ Department of Medicine, Cedars-Sinai Medical Center, Los Angeles, CA.

Correspondence: Joseph Ebinger, MD, MS, Smidt Heart Institute, Cedars-Sinai Medical

Center, 127. S. San Vicente Blvd., Suite A3100, Los Angeles, CA 90048; phone (310) 423-

0925; fax: (310) 423-4627.

NOTE: This preprint reports new research that has not been certified by peer review and should not be used to guide clinical practice. 


\section{ABSTRACT}

BACKGROUND. Use of electronic cigarettes (e-cigarettes) has increased substantially in recent years. Marketed as a safer alternative to conventional tobacco cigarettes, the safety profile of e-cigarettes is now being questioned. Importantly, the clinical consequences of ecigarette use remain poorly characterized.

METHODS. Using data from the electronic health record (EHR), we identified a cohort of ecigarette users and never-smokers in the region of central Los Angeles. Using information extracted from the EHR, we assessed temporal trends in the demographic characteristics of ecigarette users, including race/ethnicity and location of residence. We also used data on urgent medical visits (i.e. emergency department encounters and hospital admissions) occurring during the study period (January 2014 to January 2020) and employed a negative binomial regression model to compare healthcare utilization rates between e-cigarette users and never-smokers.

RESULTS. We identified a total of 698 e-cigarette users, in addition to 999 never-smokers, with demographic, clinical, and outcomes data available over the duration of the study period. From the beginning to the end of the study period, e-cigarette use increased across all race/ethnicity groups and across all geographic regions of residence. Notably, e-cigarette users experienced a 4.96 higher rate of urgent medical visits when compared to never-smokers evaluated over the same study period.

CONCLUSION. E-cigarettes use continues to expand, with evidence of racial/ethnic as well as geographic variation in uptake. Use of e-cigarette devices is associated with substantially higher rates of urgent healthcare utilization. These findings highlight the need for a more granular understanding of e-cigarette use and enhanced attention to the diversity as well as breadth of the population affected by this burgeoning health crisis. 


\section{BACKGROUD}

Electronic cigarettes (e-cigarettes) are devices that aerosolize (i.e. vaporize) liquid containing nicotine or other chemicals for inhalation. ${ }^{1}$ Use of these products has rapidly expanded, growing over $46 \%$ from years 2014 to 2017 , particularly among youth and vulnerable populations. ${ }^{2-4}$ Recent outbreaks of e-cigarette related lung injury have raised concerns about the safety of these products. ${ }^{5-11}$ To examine the diversity of persons at risk and assess the extent to which all users may be prone to developing adverse health outcomes, we assessed temporal trends in ecigarette use across a large urban medical center based population and examined associated rates of healthcare utilization. 


\section{METHODS}

We identified a cohort of e-cigarette users, leveraging electronic health record (EHR) data collected over a period of 6 years (1/1/2014 to 1/15/2020) from the Cedars-Sinai Delivery Network, a high-volume multi-site practice that serves a diverse population of over $>300 \mathrm{~K}$ unique outpatients residing in and around the greater Los Angeles area. Our EHR analytics platform was used to identify presence of e-cigarette use based on both structured and unstructured data. The analysis of unstructured data applies natural language processing along with a collection of concept matching heuristics to identify qualifying records. The applied heuristics are derived from medical ontologies using machine learning techniques, enabling longitudinal assessments to capture duration and frequency of e-cigarette use. E-cigarette use was confirmed via manual chart review performed by trained research staff. To provide comparator data, we also identified a referent group of never-smokers based on discrete data also documented in the EHR. Clinical and demographic data, including residential zip code, for all patients studied were extracted from the EHR, including the number of urgent medical visits occurring during the study period, defined as either emergency department (ED) visits or hospital admissions.

We considered baseline age for each patient as age the start of the study period (1/1/2014). We estimated median household income for patients by linking residential zip code to the 2019 American Community Survey. ${ }^{12}$ We also categorized patients' residential location using zip code matched to Service Planning Areas (SPAs), which are pre-defined geographic regions that are considered demographically meaningful by the County of Los Angeles. ${ }^{13}$ We collected and analyzed self-reported racial/ethnic data, which was considered missing if the patient refused to answer or the information was not otherwise documented in the EHR. 
medRxiv preprint doi: https://doi.org/10.1101/2020.01.20.20018275; this version posted January 27, 2020. The copyright holder for this preprint

(which was not certified by peer review) is the author/funder, who has granted medRxiv a license to display the preprint in perpetuity.

It is made available under a CC-BY-NC-ND 4.0 International license.

To compare healthcare utilization rates between e-cigarette users and never-smokers, we constructed a negative binomial regression model adjusting for age, sex, race/ethnicity, and median household income. Follow-up time for e-cigarette users was based the number of days from the first date of recorded substance use to the end of the study (1/15/2020). Follow-up time for non-smokers was calculated as the number of days from the start of the study $(1 / 1 / 2014)$ to the end of the study (1/15/2020). All study protocols were approved by the Cedars-Sinai Medical Center institutional review board, with a waiver provided for informed consent. 


\section{RESULTS}

We identified $\mathrm{N}=698$ patients with documented e-cigarette use, in addition to a cohort of $\mathrm{N}=999$ randomly selected patients with a documented history of never smoking. Overall, e-cigarette users compared to never-smokers were more likely to be younger in age and female (Table 1).

Among all e-cigarette users, racial minorities represented $21 \%$ of the population by the end of the study period (Figure 1). Asians and Native Hawaiian/Pacific Islanders were more likely to be e-cigarette users than never-smokers in our sample; by contrast, African Americans were more likely to be never-smokers (Table 1).

With respect to regional diversity, we observed an increase in e-cigarette use across all SPAs during the study period. Starting in 2017 , an increased rate of use was seen particularly in SPA

\section{5 (Figure 2).}

Overall, e-cigarette users experienced a 4.96 higher rate of urgent medical visits (i.e. emergency department visits and hospital admissions) when compared to never-smokers examined during the same study period. 


\section{DISCUSSION}

We observed that use of e-cigarettes is rapidly increasing over time, across the greater Los Angeles and surrounding areas, with evidence of racial/ethnic as well as geographic variation in uptake. Importantly, we also found that use of e-cigarette devices is associated with a substantially elevated rate of urgent healthcare utilization. These findings highlight the need for a more granular understanding of e-cigarette use at the community level and enhanced health attention to the diversity as well as breadth of the population affected by this burgeoning health crisis.

Defined geographic areas in Los Angeles, SPAs are utilized by public health officials to plan clinical services based on community needs. ${ }^{13}$ We found an increase in e-cigarette use in all SPAs, with a rapid increase in SPAs 4 and 5 starting in 2017. This likely reflects the importance of socioeconomic and community factors that underly e-cigarette use, including proximity to shops that sell the devices and advertising to specific populations. ${ }^{14-17}$ To date, our limited understanding of e-cigarette use patterns and health risk remain dependent large national surveys which often lack either longitudinal follow-up, temporal relationships between health events and granular location data, limiting efforts to assess geographic and ${ }^{36}$ social disparities. ${ }^{18-21}$ Our findings highlight that e-cigarette use rates are not changing equally in all communities and that efforts to curtail use may require locally tailored solutions.

Of particular concern is the significantly higher rate of urgent healthcare utilization among ecigarette users compared with never-smokers. While this study was unable to control for preexisting comorbid conditions, which may predispose to excess healthcare utilization, extensive evidence points to the health risks of e-cigarette use which may drive healthcare utilization. Specifically, numerous studies demonstrate that compounds found in e-cigarette vapor, such as 
Acrolein, cause adverse cardiovascular effects including reduced myocardial contractility, increased thrombosis risk and induction of vascular injury. ${ }^{22-26}$ Analyses of the National Health Interview Survey and Population Assessment of Tobacco and Health datasets demonstrate a positive association between e-cigarettes and risk of myocardial infarction; Behavioral Risk Factor Surveillance System data now clearly links e-cigarettes with an increased risk of any form of cardiovascular disease, a risk which is multiplied when these devices are used in combination with traditional cigarettes. ${ }^{27-29}$ Our study suggests that these adverse effects are not necessarily rare events, but rather are driving patients to seek urgent medical attention at markedly elevated rates.

\section{DISCLOSURES}

The authors have no relevant conflicts of interest. 


\section{REFERENCES}

1. Hajek P, Etter JF, Benowitz N, Eissenberg T and McRobbie H. Electronic cigarettes: review of use, content, safety, effects on smokers and potential for harm and benefit. Addiction. 2014;109:1801-10.

2. Bold KW, Krishnan-Sarin S and Stoney CM. E-cigarette use as a potential cardiovascular disease risk behavior. Am Psychol. 2018;73:955-967.

3. Grana R, Benowitz N and Glantz S. Response to letter regarding article, "Electronic cigarettes: a scientific review". Circulation. 2015;131:e342.

4. Delnevo CD, Giovenco DP, Steinberg MB, Villanti AC, Pearson JL, Niaura RS and Abrams DB. Patterns of Electronic Cigarette Use Among Adults in the United States. Nicotine Tob Res. 2016;18:715-9.

5. Chalon S, Moreno H, Jr., Benowitz NL, Hoffman BB and Blaschke TF. Nicotine impairs endothelium-dependent dilatation in human veins in vivo. Clin Pharmacol Ther. 2000;67:391-7.

6. Neunteufl T, Heher S, Kostner K, Mitulovic G, Lehr S, Khoschsorur G, Schmid RW, Maurer $\mathrm{G}$ and Stefenelli T. Contribution of nicotine to acute endothelial dysfunction in long-term smokers. J Am Coll Cardiol. 2002;39:251-6.

7. Gotts JE, Jordt SE, McConnell R and Tarran R. What are the respiratory effects of ecigarettes? BMJ. 2019;366:15275.

8. McConnell R, Barrington-Trimis JL, Wang K, Urman R, Hong H, Unger J, Samet J, Leventhal A and Berhane K. Electronic Cigarette Use and Respiratory Symptoms in Adolescents. Am J Respir Crit Care Med. 2017;195:1043-1049.

9. Wills TA, Pagano I, Williams RJ and Tam EK. E-cigarette use and respiratory disorder in an adult sample. Drug Alcohol Depend. 2019;194:363-370. 
10. Wang JB, Olgin JE, Nah G, Vittinghoff E, Cataldo JK, Pletcher MJ and Marcus GM. Cigarette and e-cigarette dual use and risk of cardiopulmonary symptoms in the Health eHeart Study. PLoS One. 2018;13:e0198681.

11. Itoh $\mathrm{M}$, Aoshiba $\mathrm{K}$, Herai $\mathrm{Y}$, Nakamura $\mathrm{H}$ and Takemura $\mathrm{T}$. Lung injury associated with electronic cigarettes inhalation diagnosed by transbronchial lung biopsy. Respirol Case Rep. 2018;6:e00282.

12. Bureau USC. 2013-2017 American Community Survey 5-Year Estimates - Median Household Income in the Past 12 Months (In 2017 Inflation-Adjusted Dollars), Table S1903. . $2017 ; 2020$.

13. Los Angeles County GIS Data Portal: GIS Data for LA County. 2012;2020.

14. Dai H, Hao J and Catley D. Vape Shop Density and Socio-Demographic Disparities: A US Census Tract Analysis. Nicotine Tob Res. 2017;19:1338-1344.

15. Soneji S, Pierce JP, Choi K, Portnoy DB, Margolis KA, Stanton CA, Moore RJ, BansalTravers M, Carusi C, Hyland A and Sargent J. Engagement With Online Tobacco Marketing and Associations With Tobacco Product Use Among U.S. Youth. J Adolesc Health. 2017;61:61-69.

16. Hartwell G, Thomas S, Egan M, Gilmore A and Petticrew M. E-cigarettes and equity: a systematic review of differences in awareness and use between sociodemographic groups. Tob Control. 2017;26:e85-e91.

17. Bostean G, Sanchez L and Lippert AM. Sociodemographic disparities in e-cigarette retail environment: Vape stores and census tract characteristics in Orange County, CA. Health Place. 2018;50:65-72.

18. Mirbolouk M, Charkhchi P, Kianoush S, Uddin SMI, Orimoloye OA, Jaber R, Bhatnagar A, Benjamin EJ, Hall ME, DeFilippis AP, Maziak W, Nasir K and Blaha MJ. Prevalence and Distribution of E-Cigarette Use Among U.S. Adults: Behavioral Risk Factor Surveillance System, 2016. Ann Intern Med. 2018;169:429-438. 
19. Coleman BN, Rostron B, Johnson SE, Ambrose BK, Pearson J, Stanton CA, Wang B, Delnevo C, Bansal-Travers M, Kimmel HL, Goniewicz ML, Niaura R, Abrams D, Conway KP, Borek N, Compton WM and Hyland A. Electronic cigarette use among US adults in the Population Assessment of Tobacco and Health (PATH) Study, 2013-2014. Tob Control. 2017;26:e117-e126.

20. Rigotti NA. Monitoring the Rapidly Changing Landscape of E-Cigarettes. Ann Intern Med. 2018;169:494-495.

21. Diseases loMUCoaNSSfCaSC. A Nationwide Framework for Surveillance of Cardiovascular and Chronic Lung Diseases: Existing Surveillance Data Sources and Systems. 2011.

22. Benowitz NL. Cigarette smoking and cardiovascular disease: pathophysiology and implications for treatment. Prog Cardiovasc Dis. 2003;46:91-111.

23. Yashima M, Ohara T, Cao JM, Kim YH, Fishbein MC, Mandel WJ, Chen PS and Karagueuzian HS. Nicotine increases ventricular vulnerability to fibrillation in hearts with healed myocardial infarction. Am J Physiol Heart Circ Physiol. 2000;278:H2124-33.

24. Ramachandran J, Rubenstein D, Bluestein D and Jesty J. Activation of platelets exposed to shear stress in the presence of smoke extracts of low-nicotine and zero-nicotine cigarettes: the protective effect of nicotine. Nicotine Tob Res. 2004;6:835-41.

25. Girdhar G, Xu S, Bluestein D and Jesty J. Reduced-nicotine cigarettes increase platelet activation in smokers in vivo: a dilemma in harm reduction. Nicotine Tob Res. 2008;10:1737-44.

26. Qasim H, Karim ZA, Rivera JO, Khasawneh FT and Alshbool FZ. Impact of Electronic Cigarettes on the Cardiovascular System. J Am Heart Assoc. 2017;6.

27. Alzahrani T, Pena I, Temesgen N and Glantz SA. Association Between Electronic Cigarette Use and Myocardial Infarction. Am J Prev Med. 2018;55:455-461. 
medRxiv preprint doi: https://doi.org/10.1101/2020.01.20.20018275; this version posted January 27, 2020. The copyright holder for this preprint (which was not certified by peer review) is the author/funder, who has granted medRxiv a license to display the preprint in perpetuity. It is made available under a CC-BY-NC-ND 4.0 International license .

28. Bhatta DN and Glantz SA. Electronic Cigarette Use and Myocardial Infarction Among Adults in the US Population Assessment of Tobacco and Health. $J$ Am Heart Assoc. 2019;8:e012317.

29. Osei AD, Mirbolouk M, Orimoloye OA, Dzaye O, Uddin SMI, Benjamin EJ, Hall ME, DeFilippis AP, Stokes A, Bhatnagar A, Nasir K and Blaha MJ. Association Between E-Cigarette Use and Cardiovascular Disease Among Never and Current Combustible-Cigarette Smokers. Am J Med. 2019;132:949-954 e2. 
Table 1. Demographic characteristics of e-cigarette users and never smokers. We analyzed data extracted from the Cedars-Sinai electronic health record between 1/1/2014 and 1/15/2020. Electronic cigarette use information, including start data of use, were confirmed for all patients via manual chart review. Estimated median household income was determined by linking each patient's residential zip code to data from the 2012 American Census Survey.

\begin{tabular}{|r|c|c|}
\hline \multicolumn{1}{|c|}{ Characteristics } & $\begin{array}{c}\text { E-Cigarette Users } \\
(\mathbf{N}=698)\end{array}$ & $\begin{array}{c}\text { Never-Smokers } \\
(\mathbf{N}=999)\end{array}$ \\
\hline Age in years, mean (SD) & $39.2(16.4)$ & $52.1(18.9)$ \\
\hline Female, n (\%) & $272(39.0 \%)$ & $632(63.3 \%)$ \\
\hline Race, n (\%) & & $766(76.7 \%)$ \\
\hline African American & $611(73.2 \%)$ & $150(15.0 \%)$ \\
\hline Asian & $48(6.9 \%)$ & $46(4.6 \%)$ \\
\hline Native Hawaiian/Pacific Islander & $4(0.6 \%)$ & $2(0.2 \%)$ \\
\hline American Indian/Alaska Native & $1(0.1 \%)$ & $12(1.2 \%)$ \\
\hline Missing & $38(5.4 \%)$ & $23(2.3 \%)$ \\
\hline Other & $35(5.0 \%)$ & $\$ 85,001(\$ 35,581)$ \\
\hline Household Income, est. median (SD) & $\$ 73,806(\$ 28,719)$ & \\
\hline
\end{tabular}


medRxiv preprint doi: https://doi.org/10.1101/2020.01.20.20018275; this version posted January 27, 2020. The copyright holder for this preprint (which was not certified by peer review) is the author/funder, who has granted medRxiv a license to display the preprint in perpetuity. It is made available under a CC-BY-NC-ND 4.0 International license .

Figure 1. Prevalence of e-cigarette users by racial/ethnic group per year. We analyzed data extracted from the Cedars-Sinai electronic health record between 1/1/2014 and 1/15/2020. Electronic cigarette use information, including start data of use, were confirmed for all patients via manual chart review. All data were categorized by self-reported race/ethnicity group, as documented in the medical record.

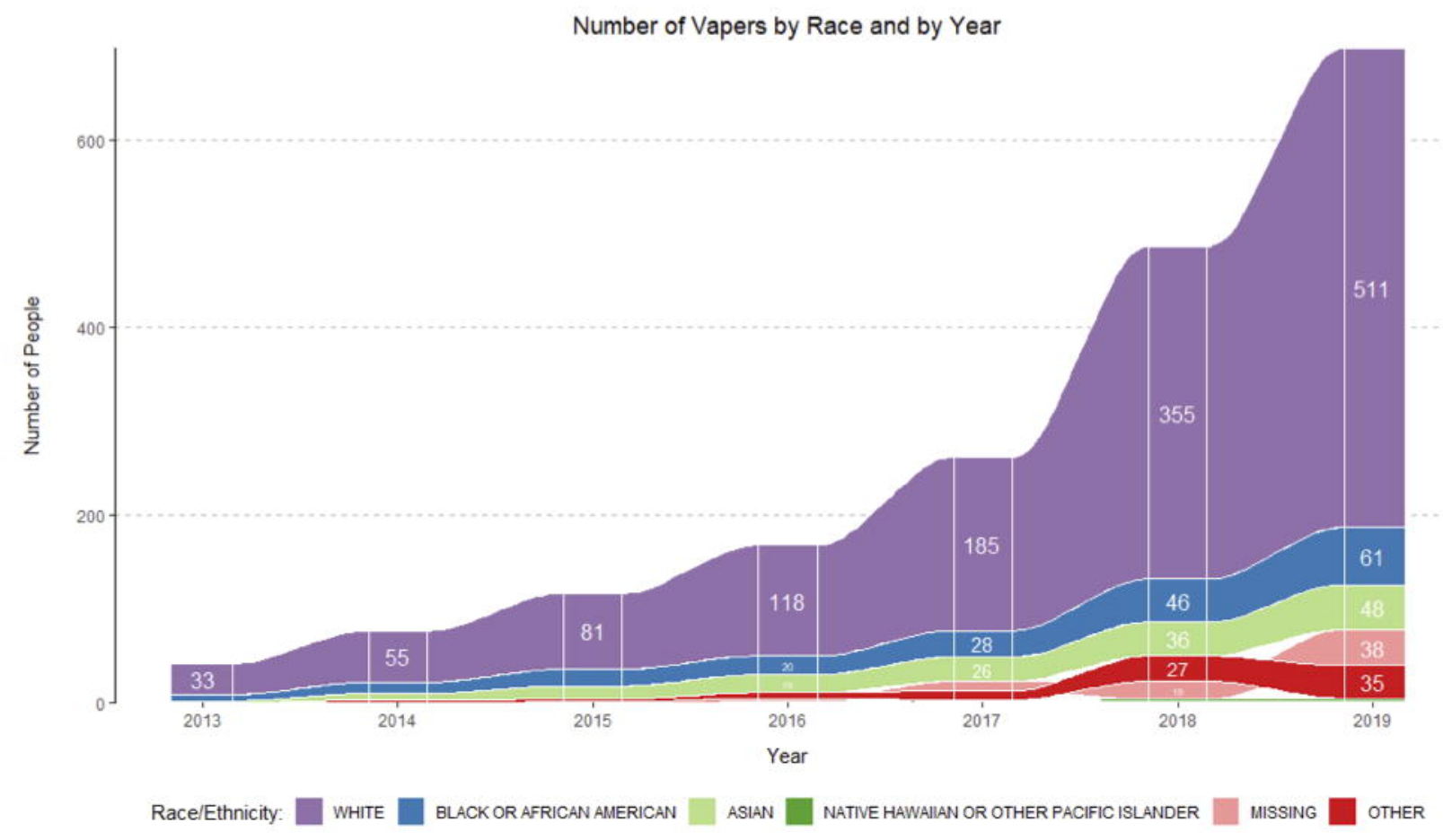


medRxiv preprint doi: https://doi.org/10.1101/2020.01.20.20018275; this version posted January 27, 2020. The copyright holder for this preprint (which was not certified by peer review) is the author/funder, who has granted medRxiv a license to display the preprint in perpetuity. It is made available under a CC-BY-NC-ND 4.0 International license .

Figure 2. Prevalence of e-cigarette users per year by region. We analyzed data extracted from the Cedars-Sinai electronic health record between 1/1/2014 and 1/15/2020. Electronic cigarette use information, including start data of use, were confirmed for all patients via manual chart review. Patient region of residence, based on service planning area (SPA), was determined by linking residential zip codes to the Los Angeles County SPA database key.

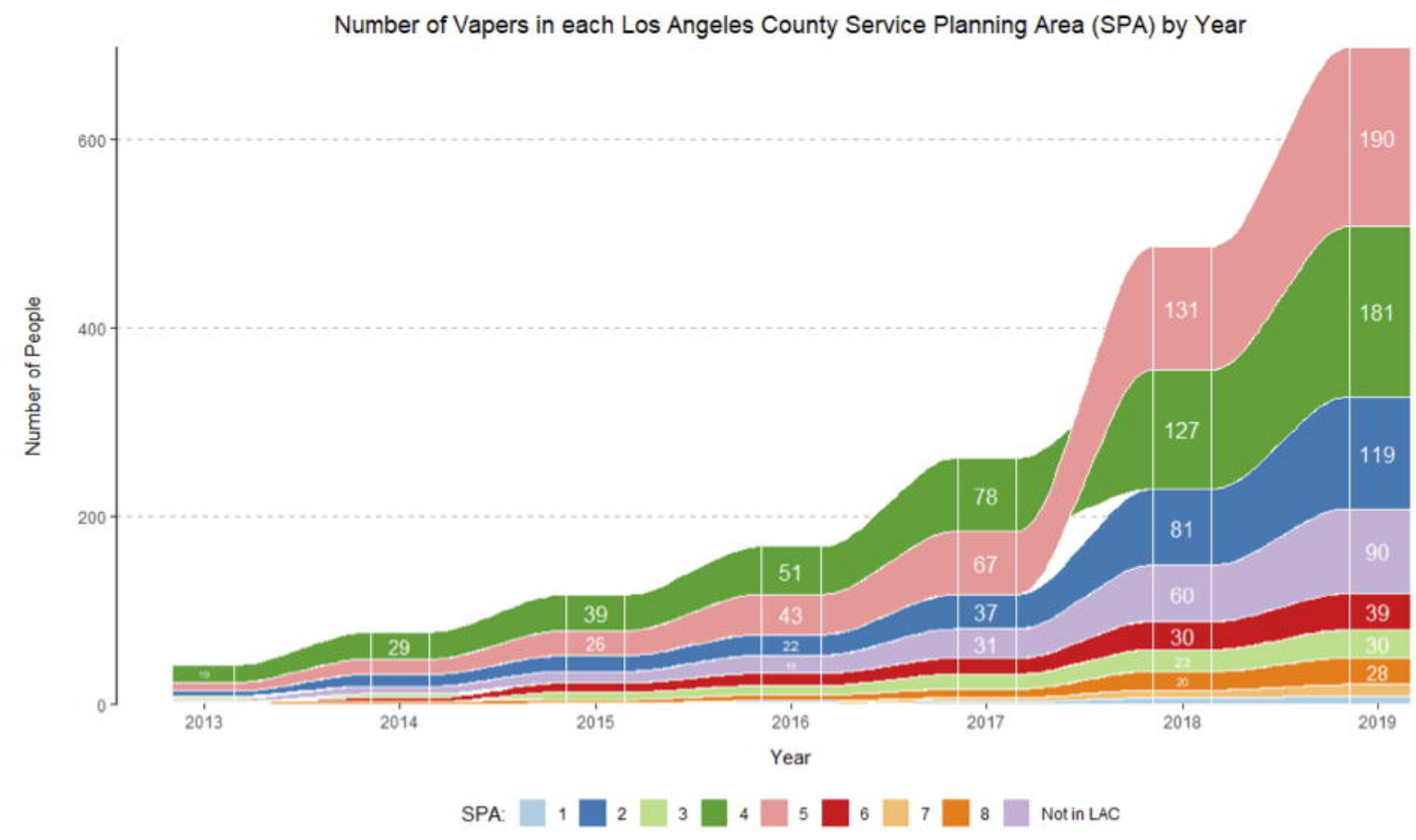

